\title{
Evacuated Tube Solar Collectors Integrated with Phase Change Materials
}

\author{
Alexios Papadimitratos ${ }^{\mathrm{a}}$, Sarvenaz Sobhansarbandi ${ }^{\mathrm{b}}$, Vladimir Pozdin ${ }^{\mathrm{a}}$, \\ Anvar Zakhidov ${ }^{\mathrm{c}, \mathrm{d}}$, Fatemeh Hassanipour ${ }^{\mathrm{b}, *}$ \\ ${ }^{a}$ Solarno Inc., Coppell, TX, 75019 \\ ${ }^{b}$ University of Texas at Dallas, Department of Mechanical Engineering \\ Richardson, TX, 75080 \\ ${ }^{c}$ University of Texas at Dallas, Department of Physics \\ Richardson, TX, 75080 \\ ${ }^{d}$ Energy Efficiency Center, National University of Science and Technology, MISIS, \\ Moscow, Russia,119049
}

\begin{abstract}
This paper presents a novel method of integrating phase change materials (PCMs) within the evacuated solar tube collectors for solar water heaters (SWHs). In this method, the heat pipe is immersed inside the phase change material, where heat is effectively accumulated and stored for an extended period of time due to thermal insulation of evacuated tubes. The benefit of this method includes improved functionality by delayed release of heat, thus providing hot water during the hours of high demand or when solar intensity is insufficient. The proposed solar collector utilizes two distinct phase change materials (dual-PCM), namely Tritriacontane and Erythritol, with melting temperatures of $72^{\circ} \mathrm{C}$ and $118^{\circ} \mathrm{C}$ respectively. The operation of solar water heater with the proposed solar collector is investigated during both normal and on-demand operation. The feasibility of this technology is also tested via large scale commercial solar water heaters. Beyond the improved functionality for solar water heater systems, the results from this study show efficiency improvement of $26 \%$ for the normal operation and $66 \%$ for the stagnation mode, compared with standard solar water heaters that lack phase change materials.
\end{abstract}

\footnotetext{
*Corresponding author

Email address: fatemeh@utdallas.edu (Fatemeh Hassanipour)

URL: http://www.utdallas.edu/ fatemeh (Fatemeh Hassanipour)
} 
Keywords: Evacuated tube collectors, Solar water heater, Phase change material

\section{Nomenclature}

$A_{c} \quad$ Solar collectors surface area $\left(m^{2}\right)$

$c_{p_{w}} \quad$ Specific heat of water $(k J / k g K)$

$c_{p_{l}} \quad$ Specific heat of PCM liquid phase $(k J / k g K)$

$c_{p_{s}} \quad$ Specific heat of PCM solid phase $(k J / k g K)$

$G_{t} \quad$ Global radiation $\left(W / m^{2}\right)$

$H \quad$ Latent heat of fusion $(k J / k g)$

$\dot{m} \quad$ Mass flow rate $(\mathrm{kg} / \mathrm{s})$

$T_{\text {Fin }} \quad$ Fin temperature $\left({ }^{\circ} \mathrm{C}\right)$

$T_{m} \quad$ Melting temperature $\left({ }^{\circ} \mathrm{C}\right)$

$T_{W} \quad$ Water temperature $\left({ }^{\circ} \mathrm{C}\right)$

$T_{W_{f}} \quad$ Final water tank temperature $\left({ }^{\circ} \mathrm{C}\right)$

$T_{W_{i}} \quad$ Initial water tank temperature $\left({ }^{\circ} \mathrm{C}\right)$

$\eta_{s} \quad$ Efficiency of the solar water heater $(\%)$

$\rho_{l} \quad$ Density of PCM liquid phase $\left(\mathrm{kg} / \mathrm{m}^{3}\right)$

$\rho_{s} \quad$ Density of PCM solid phase $\left(\mathrm{kg} / \mathrm{m}^{3}\right)$

\section{Introduction}

Solar collectors absorb the radiation from the sun and transform it to heat via a transfer medium. Two prevalent collector formats are Flat Plate Collector (FPC) and Evacuated Tube Collector (ETC). One advantage of evacuated tube solar collectors is that they are relatively insensitive to the direction of sunlight, while flat plates can suffer from additional reflection if the direction of sunlight is not suitable. Evacuated tube collectors also have better thermal insulation in comparison with the flat plate collectors. Evacuated tubes consist of two concentric glass tubes that are sealed at the ends and the inner tube is coated with a solar selective coating. High vacuum is produced between the two tubes, thus eliminating convection loss and providing excellent thermal insulation. When the tube is exposed to the sun, the solar selective coating absorbs the solar energy and transfers it to a heat pipe that is located inside the inner tube. The heat pipe contains a heat 
transfer fluid (typically water or ethylene glycol) that transfers the heat to the system's manifold. The liquid in the heat pipe has a low boiling point, so when it is heated, the liquid inside the pipe begins to vaporize and rapidly rises to the top of the heat pipe while carrying a large amount of energy to the manifold. As the heat is off-loaded to the manifold, the vapor condenses and liquid returns to the bottom of the heat pipe. An aluminum fin, held in the tube by a spring clip, facilitates heat transfer and mechanically supports the heat pipe in place. A schematic configuration of the evacuated tube solar collectors is shown in Figure 1.

This paper studies evacuated tube collectors, in particular, in the context of solar water heaters. A solar water heater system often needs a booster (storage unit) to provide heat whenever little or no solar energy is available. Efficient development of such storage devices have been widely studied (Cabeza et al., 2006; El Qarnia, 2009; Font et al., 1994; PBL, 2000; Prakash et al., 1985; Rabin et al., 1995; Sharma A, 2003; Tarhan et al., 2006; Tayeb, 1995; Tiwari et al., 1988; Mehling et al., 2003). Among various methods for heat storage, the use of solid-liquid phase change materials, has attracted considerable attention (Al-Jandal and Sayigh, 1994; Boy et al., 1987; Cabeza et al., 2006; El Qarnia, 2009; Ghoneim, 1989; Waschull et al.; Kürklü et al., 2002; Lee et al., 2006; Mettawee and Assassa, 2006; PBL, 2000; Rabin et al., 1995; Sharma et al., 2009; Tarhan et al., 2006; Tayeb, 1993; Tiwari et al., 1988; Talmatsky and Kribus, 2008; Mehling et al., 2003). There is a large variety of PCMs (e.g. water, salt hydrates, certain hydrocarbons, metal alloys, and paraffin) that melt and solidify at a wide range of temperatures, making them attractive for the purpose of energy conservation in a number of applications. PCMs have a high latent heat capacity, and by going through melting/solidification phase, can store 5 to 14 times more heat per unit volume than sensible storage materials while the absorption and release of heat happen at a nearly constant temperature (Sharma et al., 2009). Representative examples of work, based on the application of PCM in solar water heaters are discussed below, where typically the PCM is placed inside the water tank of SWH.

Prakash et al. (1985) studied a water heater system with a separate storage tank, which contained a layer of encapsulated PCMs at the bottom of the tank. Boy et al. (1987) proposed an integrated collector storage system based on a salt-hydrate PCM for providing hot water instantaneously, claiming that the thermal efficiency can be improved significantly by incorporating an appropriate PCM. However, the cost of the system was increased because 
the salt-hydrate PCM was encapsulated in a special corrugated-fin heat exchanger. Tiwari et al. (1988) analyzed a phase change component material storage system for water heaters by incorporating the effect of water flow through a parallel plate placed at the solid-liquid interface. Ghoneim (1989) compared the performance of PCMs by considering the heat conduction and heat loss from the storage unit for both air and water-based solar heating systems and investigated the required storage capacity. Bansal and Buddhi (1992) theoretically studied a cylindrical latent heat storage system for a domestic hot water system where during the charging mode of the phase change material, the cylindrical capsule is in the closed loop with a solar water heater, and during the discharging mode, the energy is extracted by a liquid flowing through the storage unit. Tayeb $(1993,1995)$ developed a system for domestic hot water using PCM in the storage media and compared its performance with a simulation model. This work demonstrated the optimum flow rate of the inlet water supply for maintaining constant water temperature at the outlet. Al-Jandal and Sayigh (1994) studied the combination of solar collectors and PCM in one unit (similar to a heat exchanger) via both analytical and experimental analysis on a direct contact PCM solar storage system with water, using two vertical cylindrical concentric tubes with Stearic Acid PCM between them. Font et al. (1994) conducted a preliminary study for the design of a device for domestic water heater using a solid-solid PCM. In this work, water flows through the PCM in the restitution period, in the same circuit as in the charge period. Kaygusuz (1995) studied the performance of the thermal energy storage materials, collectors and energy storage tank filled by the PCMs, for domestic heating.

Kürklü et al. (2002) developed a new type of solar flat panel collector consisting of two adjoining sections, one filled with water and the other with a paraffin wax PCM. Canbazoğlu et al. (2005) investigated the energy storage duration of hot water, the produced hot water, and the total heat accumulated in the solar water storage tanks combined with PCM. Cabeza et al. (2006) constructed a water heater system by adding a PCM module at the top of the water tank, compensating heat loss from the top layers. They applied several cylinders at the top of the water tank and investigated the system performance with two, four and six PCM modules. Mettawee and Assassa (2006) investigated the thermal performance of a single unit PCM solar flat panel collector, where the absorber plate-container unit performs simultaneously as a solar energy absorber and PCM storage medium. Tarhan et al. (2006) experimentally evaluated three trapezoidal built-in storage solar 
water heaters to study the effects of PCM types, the location of the PCM storage units, and the absorbing plates on the performance of the solar water heater. Lee et al. (2006) experimentally studied a latent heat storage unit in a two-phase thermosyphon solar water heater. Nallusamy et al. (2007) investigated experimentally the thermal behavior of a packed bed of combined sensible and latent heat thermal energy storage unit for a solar water heater. Hassan and Beliveau (2008) proposed a solar energy collection system that consists of an integrated flat-plate collector and a PCM storage tank in one functional unit. Browne et al. (2015) investigated experimentally the performance of a photovoltaics/thermal phase change material system where the stainless steel container of water pipe network is filled with PCM.

Seeniraj and Narasimhan (2008) studied numerically the performance of a latent heat thermal system unit with both finned-tube and multiple PCM employing an enthalpy-based model with application in solar energy. The shell side contains five different PCMs and the tube side (though unevacuatedconventional tube) has an arrangement of radial fins with uniform thicknesses that carry the fluid. Sharma et al. (2009) compared the performance of PCM, water, and rock based storage system. El Qarnia (2009) studied a theoretical model to predict the thermal behavior and performance of a solar latent heat storage unit that consists of a series of identical tubes embedded in the PCM. In their experiment, a heat transfer fluid from the solar collector passes through the tubes and transfers the absorbed solar radiation energy to the PCM inside the storage tank.

Until now, the PCM-based storage unit has been designed either as a separate medium away from the solar collectors or directly applied inside the flat panel collectors. This paper proposes a new system that combines the heat collection and the PCM-storage system both in a single unit, inside the evacuated tube solar collectors (Figure 2). To the best of the authors' knowledge, this is the first study of the integration of PCM inside the evacuated solar tubes. This paper describes the addition of phase change materials inside typical evacuated tube solar collectors to improve their functionality by storing energy in the system during on-demand operation. This concept can be applied to provide delayed heat to a system when solar energy is insufficient or unavailable at night and on cloudy days.

In general, water heater demand (in $\mathrm{kW}$ ) in a household varies during the season and also during the day. On a daily basis, the demand peaks in the morning and late evening hours can be seen in (Figure 3). The motivation for our technology of PCM within evacuated tube solar collectors, is to address 
the evening peak demand with energy storage in PCM, independently of weather conditions and time.

\section{Experimental Study}

The experimental study in this paper has three phases:

- Phase-I: Selecting the proper phase change material for the application of evacuated tube solar collectors.

- Phase-II: Testing the performance of the PCM integrated solar water heater system in both normal and on-demand operations.

- Phase-III: Optimization of the PCM integrated water heater system based on the obtained results from the previous phases.

The details of each phase and its related approaches and results are outlined below:

\subsection{Phase-I: Selection of Proper Phase Change Materials}

PCMs can be divided into two broad categories of high melting temperature (above $100^{\circ} \mathrm{C}$ ) and low melting temperature (below $100{ }^{\circ} \mathrm{C}$ ). Among the low melting temperature PCMs, paraffins with chemical formulation $\left(C_{n} H_{2 n+2}\right)$ have stable physical/chemical properties, no toxicity and no fire hazard, low cost and high availability. These characteristics make them attractive for the application of heat storage in solar collectors. Paraffins have a large spectrum of latent heat capacities $(220-270 \mathrm{~kJ} / \mathrm{kg})$ and melting temperatures $\left(5.5-80{ }^{\circ} \mathrm{C}\right)$ based on their number of carbons $(n)$. Therefore, for heat storage purposes, proper paraffins can be selected based on their melting/solidification temperature and also the system's operating temperature.

Although paraffins with low melting temperature are good candidates for solar storage applications (as a separate tank), not all paraffins are suitable for the inside of the evacuated tube collectors. The reason is that the temperature inside the evacuated tubes may reach up to $180{ }^{\circ} \mathrm{C}$ due to the vacuum layer. Therefore, selection of PCM with appropriate melting temperature and stability is challenging for the heat storage functionality inside the collector tubes.

Phase change materials with high melting temperature (above $100{ }^{\circ} \mathrm{C}$ ) usually have high cost, subcooling, and poor stability during the temperature cycling. Therefore, the number of suitable phase change materials with 
high melting temperature is limited (Waschull et al.). Among the proposed PCMs in literature (Table 1), we have chosen Erythritol in the current study. Erythritol is a widely available sugar alcohol with the melting point of 118 ${ }^{\circ} \mathrm{C}$ and latent heat capacity of $340 \mathrm{~kJ} / \mathrm{kg}$. Clinical studies confirm that Erythritol is a non-toxic and safe material; its level of non-toxicity can be highlighted by the fact that it is used in the food industry as sweetener (Munro et al., 1998). Compared with other sugar substitutes, Erythritol does not caramelize when heating up. The thermophysical properties of Erythritol are shown in Table 2.

For comparative purposes, we also study two types of paraffins for application in evacuated tubes. These paraffins are Hexacosane and Tritriacontane, with melting temperature of $56^{\circ} \mathrm{C}$ and $72{ }^{\circ} \mathrm{C}$ respectively. The chemical formulas and physical properties of these PCMs are shown in Table 2( Himran et al. (1994); Zalba et al. (2003); Kakiuchi et al. (1998); Takahashi (2013)).

A bench-top (small size) Apricus evacuated solar water heater system (Model\# 513) is chosen for the phase-I of the study (Figure 4). In this experiment, the inner space of three individual tubes are filled with Hexacosane, Tririacontane, and Erythritol PCMs while the aluminum fins are in place. After capping the tubes, they are placed under sunlight for several hours to make sure the PCMs are fully melted. Once the tubes are removed from the sunlight and moved indoor, the heat pipes attached to a $600 \mathrm{ml}$ water tank, (with initial temperature of $25{ }^{\circ} \mathrm{C}$ ) are inserted into the tubes (Figure 5). The temperature inside the evacuated tubes attached to the aluminum fins $\left(T_{\text {Fin }}\right)$ and the water tank $\left(T_{W}\right)$ are recorded for two hours, during which the system settles into a steady condition. The latent heat inside the PCMs are released during the solidification process and initiates the temperature reduction inside the tube (Figure 6a). At the same time, heat pipes transfer heat from the PCM to the tank, therefore the temperature of water inside the tank increases (Figure 6b). A temperature rise of $9^{\circ} \mathrm{C}$ in the water tank is recorded for Hexacosane material, and $18^{\circ} \mathrm{C}$ for Tritriacontane paraffin. For the Erythritol which has higher melting temperature and latent heat capacity, the temperature increase is around $36^{\circ} \mathrm{C}$.

Erythritol provided the most desirable (highest) temperature rise, however, immediately after heat pipe insertion, Erythritol rapidly solidified inside the tubes. This sudden spot heating/cooling causes non-uniform Erythritol volume expansion/contraction. We observed as high as $13 \%$ volume expansion for the Erythritol during heating cycles which can result in the cracking of the glass tube. Therefore, despite the promising fundamentals of the pre- 
liminary results, a solution was needed for practical usage of Erythritol in evacuated collectors. This problem is solved by placing Erythritol inside small aluminum bags (Figure 7) while leaving some space for the expansion of that during the melting process. To avoid sudden spot heating/cooling around the bags, Silicon oil is injected in the tubes between the void spaces between the bags. Silicon oil increases convective heat transfer (stirring effect) which leads to a uniform melting inside the Erythritol bags and prevents tube breakage or malfunction. Two thermocouples are installed on top (facing sunlight) and bottom (facing the ground) of the Erythritol bags (Figure 7) to monitor the melting process of Erythritol during different hours of the day.

\subsection{Phase-II: Normal vs. Stagnation Operation}

In the second phase of the experiment, a standard Apricus collector is used to facilitate the comparison of the performance of identical commercial evacuated tubes simultaneously with and without phase change materials. The commercial Apricus solar collector has 10 evacuated tubes which four tubes are left untouched (no PCM), three tubes are filled with Tritriacontane paraffin ( $2 \mathrm{~kg}$ per tube), and three tubes with Erythritol baggies (1.4 $\mathrm{kg}$ per tube) and silicon oil. Total latent heat capacity of PCM integrated tubes are almost equal due to the higher latent heat capacity of the Erythritol compared with paraffin. Each setup includes an immersion pump inside the storage tanks with $40 \mathrm{~L}$ capacity to circulate the water in the system and a flow meter that controls the water flow-rate entering the manifold.

Several thermometers record the temperature inside each evacuate tube $\left(T_{\text {Fin }}\right)$ which are attached to the aluminum fin, and water tank $\left(T_{W}\right)$ during the test (Figure 8). The thermocouple readings are recorded with an OMEGA HH309A thermometer with accuracy $\pm 0.2 \%$. The repeatability and accuracy of measurements are examined by monitoring the solar irradiation using a SP-Lite2 Pyranometer (directional error (up to $80^{\circ}$ with 1000 $\mathrm{W} / \mathrm{m}^{2}$ beam) less than $10 \mathrm{~W} / \mathrm{m}^{2}$ ) during the consecutive days of experiment. A sample of recorded data has been plotted in Figure 9.

Among the efficient phase change materials tested in phase-I, Tritriacontane paraffin and Erythritol are chosen for the second phase of the experiment to study their effect on the storage capacity in both normal and on-demand operation by keeping the collectors initially stagnated for an extended period of time before water flow circulation. In "normal operation", water is continuously circulating through the manifold during the day. "On-demand operation" (stagnation mode) is unique to our SWH systems with PCM. 
The PCM inside the evacuated tube collector acts as a storage medium for releasing heat at a later time for providing hot water in a specific time of the day once the water flow restarts. In this experiment, the SWH system is kept in stagnation mode with no water circulation while the collectors absorb the solar radiation continuously, which results in trapping the heat in the tubes (maximum energy storage). Temperature variation inside the evacuated tubes are shown in Figure 10 for both normal and stagnation operation mode.

Under normal operation (Figure 10a), the temperature inside the tubes increases, eventually stabilizing at a maximum value. The results show that standard tubes are heated up to $140^{\circ} \mathrm{C}$, while the PCM integrated tubes after similar exposure to sunlight to reach to the temperature around $90 \pm 10^{\circ} \mathrm{C}$. The rate of cooling in a typical tube with no PCM is very fast, with the temperature falling within a few minutes. In the case of PCM filled tubes, the cooling process is significantly slower and the heat pipe can operate for several hours. The paraffin filled tube temperature shows a higher latent heat release compared with the Erythritol filled tubes, where the heat release happens around $75^{\circ} \mathrm{C}$. The reason is that, due to higher melting temperature of Erythritol compared to paraffin, Erythritol does not fully melt and shows less latent heat release. In summary, paraffin filled tubes show better performance in normal operation mode compared with Erythritol filled tubes.

Figure 10b presents the inner tube temperatures recorded during the cooling process after the stagnation mode. To mimic the stagnation mode on the second system, no water flow is initiated through the manifold for an extended time until the PCMs in the tubes completely melt, then the system (collectors) were covered completely from sun and water circulation starts by switching the pump on. It is observed that the initial temperature inside the standard tubes reach $200^{\circ} \mathrm{C}$, for paraffin tubes temperature is around $155^{\circ} \mathrm{C}$ and for Erythritol tubes around $130^{\circ} \mathrm{C}$. The PCM tubes initial temperatures are above their related melting point, therefore phase change (melting) process has occurred for the majority of the paraffin and Erythritol material. After switching the pump on, energy transfers to the water through the heat pipe and the manifold. The paraffin tube temperature curve shows a plateau around $70^{\circ} \mathrm{C}$, and Erythritol tube shows a plateau around the transition temperature of $100^{\circ} \mathrm{C}$.

As observed, during stagnation operation (on-demand), Erythritol filled tubes show an improved performance with higher storage capacity compared with paraffin filled tubes. It can be seen that, as in the stagnation operation 
the temperature inside the tubes can reach to a higher value compare to the normal operation, so it allows the Erythritol to be fully melted this time, so the Erythritol would have higher rate of heat storage capacity and consequently results in the slower cooling rate inside the tubes. The delayed cooling of PCM collectors can extend operation of SWH systems when solar radiation is not enough (after sunset).

\subsection{Phase-III: Dual-PCM Solar Water Heater}

In the third phase of the experiment, two standard Apricus large scale evacuated tube collectors are used to demonstrate the feasibility of the proposed approach in commercially available solar water heaters. The experimental setup is designed to facilitate the comparison of the performance of identical commercial evacuated tube solar collector arrays simultaneously with and without phase change materials.

The effect of PCM on the solar water heater operation is even more pronounced when comparing the recorded water temperatures in the storage tanks. Based on the results from Phase-II, a dual-PCM solar water heater system is proposed with improved performance in both normal and on-demand operation. The dual-PCM system includes a large scale Apricus solar collector with five tubes filled with paraffin and five tubes filled with Erythritol. A standard (No PCM) and dual systems work simultaneously under similar situation as seen in Figures 11 and 12.

The results for the water temperature in the storage tanks of both standard and dual-PCM are shown in Figure 13 in normal and stagnation operation. While water temperature in storage tanks of both systems are almost $50^{\circ} \mathrm{C}$ around 5:00 PM, the dual PCM system has a longer delayed cooling period and keeps water in higher temperature compared with standard system during the evening and at night when solar radiation is not available (Figure 13a). The hatched area is a representative of the improved heat storage capacity for the dual-PCM system compared with the standard one during the normal operation.

For the stagnation mode testing, the PCMs inside the dual-PCM system are fully melted before the water circulation initiates. Figure 13b shows the recorded temperature of both systems during the cooling process after the stagnation mode. Fast cooling in standard system and delayed cooling of dual-PCM system are observed. While both systems are stagnated, the majority of absorbed energy is accumulated in the PCMs and once the water flow is started, the energy can be transferred to water through the heat pipe 
and the manifold assembly. Therefore, the dual-PCM solar water heater system allow the operation of the system for a longer period of time when sunlight is not available. The hatched area in Figure 13b represents the improved heat storage capacity of the dual-PCM solar water heater system in the stagnation mode compared with the standard one with no PCM.

Based on the latent heat storage of each PCM, the total energy storage can be calculated as multiplying the mass by latent heat of each PCMs and it can be written as following:

$$
Q=m_{\text {Tritriacontane }} H_{\text {Tritriacontane }}+m_{\text {Erythritol }} H_{\text {Erythritol }}
$$

where $\mathrm{m}$ is the mass of Tritriacontane and Erythritol in $\mathrm{kg}$ ( $2 \mathrm{~kg}$ of Tritriacontane and $1.4 \mathrm{~kg}$ Erythritol per tube), and $\mathrm{H}$ is the latent heat capacity of Tritriacontane and Erythritol in $\mathrm{kJ} / \mathrm{kg}$. The total amount will be:

$$
Q=(5)(2 k g)(256 k J / k g)+(5)(1.4 k g)(339.8 k J / k g)=4938.6 k J
$$

This value represents the energy storage capacity of PCMs in the current configuration.

The gray area (Evening Peak Zone) presents an overall perceptive of maximum average hourly energy demand $(\mathrm{kW})$ for the residential solar water heaters during the summer and winter times (Carlos J.Colon, 2010). As shown, an improved performance and functionality of the dual-PCM solar water heater during this peak zone is achieved. In this regard, the system efficiency can be obtained from the following equation, based on the maximum temperature gradient in the storage tank during the normal and stagnation operation of the system (Sukhatme and Sukhatme, 1996):

$$
\eta_{s}=\frac{\dot{m} c_{p_{w}}\left(T_{w, f}-T_{w, i}\right)}{A_{c} G_{t}}
$$

where $\dot{m}$ is the water mass flow-rate which in our experiment is around 0.0126 $\mathrm{kg} / \mathrm{s}, c_{p_{w}}$ is the specific heat capacity of water which is $4.186 \mathrm{~kJ} / \mathrm{kg} . \mathrm{k}$, and $T_{w, i}$ and $T_{w, f}$ are initial and final water temperatures in the storage tank. $A_{c}$ is the collector gross area which is $1.6 \mathrm{~m}^{2}$ (AP-10 gross area), and $G_{t}$ is the total global radiation on the surface of the collectors which is measured by the SP-Lite2 Pyranometer and shows the maximum amount of $947 \mathrm{w} / \mathrm{m}^{2}$ on the selected days (Figure 9).

The recorded temperatures show a maximum temperature gradient between the standard and Dual-PCM systems as $\Delta T_{\max }=8^{\circ} \mathrm{C}$ in normal 
operation and $\Delta T_{\max }=15^{\circ} \mathrm{C}$ in stagnation mode. Based on this calculation, the efficiency of the Dual-PCM solar water heater system has increased $26 \%$ compared with standard system in normal operation and $66 \%$ in stagnation mode.

\section{Conclusion}

This paper presents the performance of a solar water heater with evacuated tubes integrated with phase change materials. The results show that phase change material integrated inside the inner tubes of evacuated tube solar collectors can effectively store energy (in the form of latent heat) next to the heat pipes and enable a delayed cooling after sunset or late evening. The proposed solar collector utilizes two distinct phase change materials (dualPCM), namely Tritriacontane and Erythritol with melting temperature $72^{\circ} \mathrm{C}$ and $118^{\circ} \mathrm{C}$ respectively. The operation of solar water heater with the proposed solar collector is investigated during both normal and on-demand operation. The feasibility of this technology is tested via large scale commercial solar water heaters. This study shows a significant efficiency improvement of dual-PCM solar water heaters for both normal and stagnation operation, compared with standard solar water heaters that lack phase change materials.

\section{Acknowledgment}

This work was supported by the U.S. Department of Energy (DOE) under the STTR award number DE-SC0009447. The authors would like to thank Apricus Inc. for the donation of the evacuated tubes solar collectors and Mr. Mick Humphreys for useful discussions. Partial financial support from the Ministry of Education and Science of the Russian Federation in the framework of Increase Competitiveness Program of NUST-MISiS (No. $\mathrm{K} 2-2015-014)$ is also appreciated. 
368

369

370

371

372

\section{List of Tables}

1 Phase change materials with high melting temperature . . . 14

2 Thermophysical properties of Hexacosane, Tritriacontane and Erythritol Himran et al. (1994); Zalba et al. (2003); Kakiuchi et al. (1998); Takahashi (2013) . . . . . . . . . . . . . . . 15 
Table 1: Phase change materials with high melting temperature

\begin{tabular}{|l|c|c|}
\hline Substance & Melting Temperature $\left({ }^{\circ} \mathrm{C}\right)$ & Latent Heat $(\mathrm{kJ} / \mathrm{kg})$ \\
\hline Erythritol & 119 & $332-340$ \\
\hline Pentaerythritol & $186-187$ & $287-298$ \\
\hline Azelais acid & $98-108$ & 174 \\
\hline Sebacic acid & $130-134$ & 228 \\
\hline Dimethyl Terephthalate & 142 & 170 \\
\hline P-Toluic acid & 180 & 167 \\
\hline Octadecanamide & 106 & 211 \\
\hline Urea & $133-135$ & $170-258$ \\
\hline
\end{tabular}


Table 2: Thermophysical properties of Hexacosane, Tritriacontane and Erythritol Himran et al. (1994); Zalba et al. (2003); Kakiuchi et al. (1998); Takahashi (2013)

\begin{tabular}{|l|c|c|c|c|}
\hline Properties & Hexacosane & Tritriacontane & Erythritol & Silicon Oil \\
\hline Chemical Formula & $C_{26} H_{54}$ & $C_{33} H_{68}$ & $C_{4} H_{10} O_{4}$ & - \\
\hline$T_{m}\left({ }^{\circ} \mathrm{C}\right)$ & 56 & 72 & 119 & - \\
\hline$H(k J / k g)$ & 250 & 256 & 339.8 & - \\
\hline$c_{p_{l}}(k J / k g K)$ & 0.87 & 1.11 & 2.76 & - \\
\hline$c_{p_{s}}(k J / k g K)$ & 0.68 & 0.87 & 1.38 & - \\
\hline$\rho_{l}\left(k g / m^{3}\right)$ & 765 & 782 & 1300 & 960 \\
\hline$\rho_{s}\left(k g / m^{3}\right)$ & 800 & 810 & 1480 & 960 \\
\hline FiringPoint $\left({ }^{\circ} \mathrm{C}\right)$ & - & - & - & 318 \\
\hline
\end{tabular}




\section{List of Figures}

1 A schematic of evacuated tube solar collector and its crosssectional view . . . . . . . . . . . . . . . . . . 17

2 Schematic of evacuated solar collector filled with PCM . . . . 18

3 Daily residential water heater demand $(\mathrm{kW})$ in summer and winter (Carlos J.Colon, 2010) . . . . . . . . . . . . . . . . . 19

4 Phase-I: Experimental apparatus . . . . . . . . . . . 20

5 Phase-I: Schematic Configuration of Experimental setup . . . 21

6 Phase-I: (top) Temperature inside the tubes, and (bottom) Temperature of the water tank . . . . . . . . . . . . . 22

7 A schematic configuration of evacuated solar tubes filled with Erythritol baggies and silicone oil flow . . . . . . . . . . 23

8 Phase-II: Schematic Configuration of Experimental Setup . . . 24

9 A sample of solar radiation recorded by Pyranometer . . . . . 25

10 Phase II: Temperature inside the evacuated tubes, (top) Normal operation, and (bottom) Stagnation operation . . . . . . 26

11 Phase-III: Experimental apparatus . . . . . . . . . . . . . 27

12 Phase-III: Schematic Configuration of Dual-PCM Experimental Setup . . . . . . . . . . . . . . . . . . 28

13 Phase III: Water temperature, (a) Normal operation, and (b) Stagnation operation . . . . . . . . . . . . . . . . . . . 29 


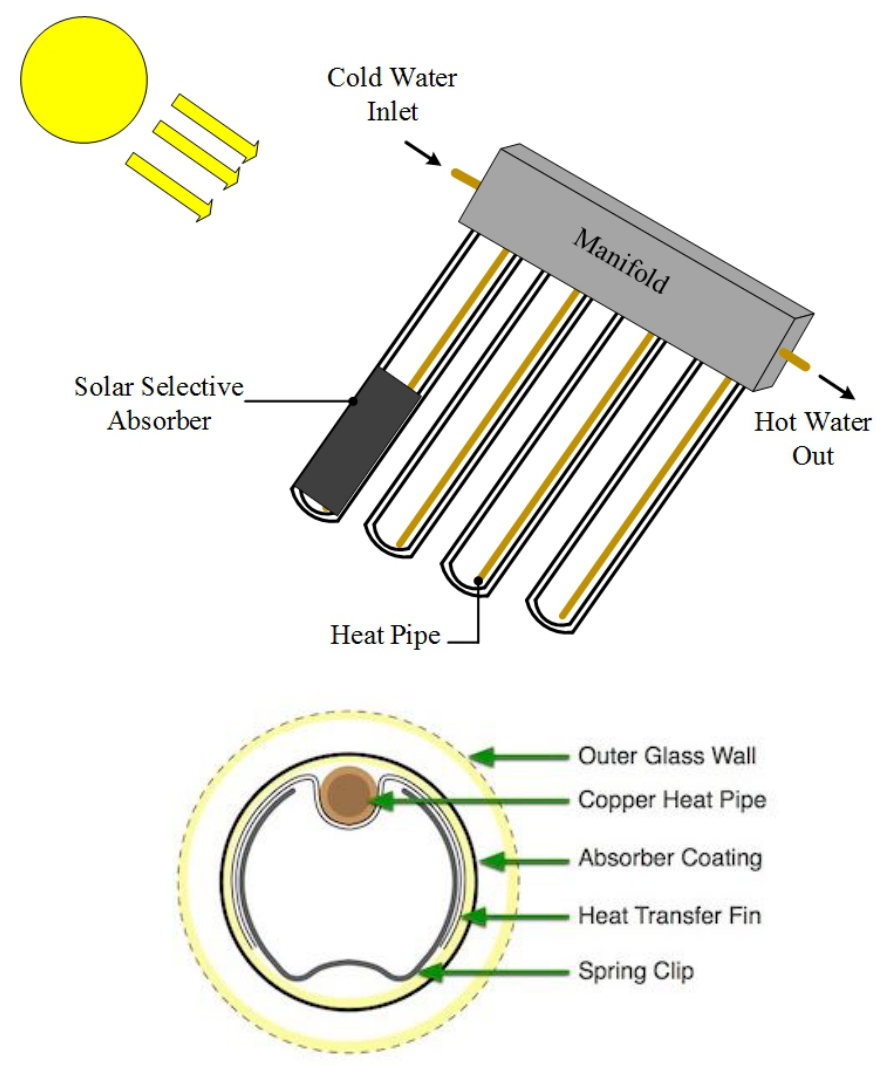

Figure 1: A schematic of evacuated tube solar collector and its cross-sectional view 


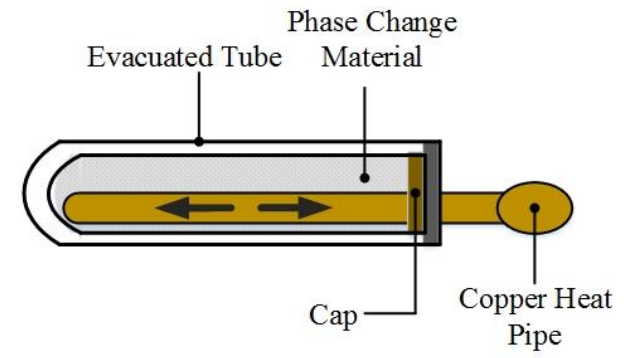

Figure 2: Schematic of evacuated solar collector filled with PCM 


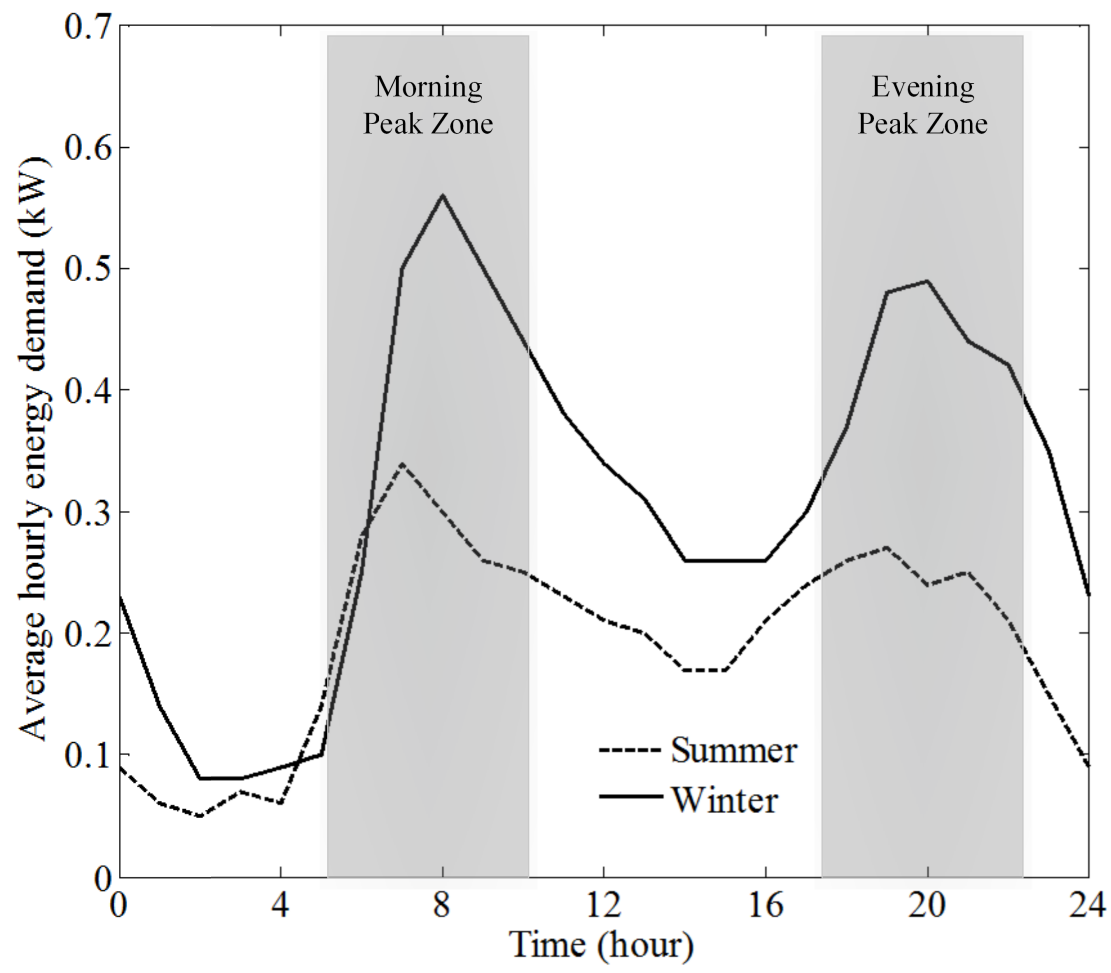

Figure 3: Daily residential water heater demand $(\mathrm{kW})$ in summer and winter (Carlos J.Colon, 2010) 

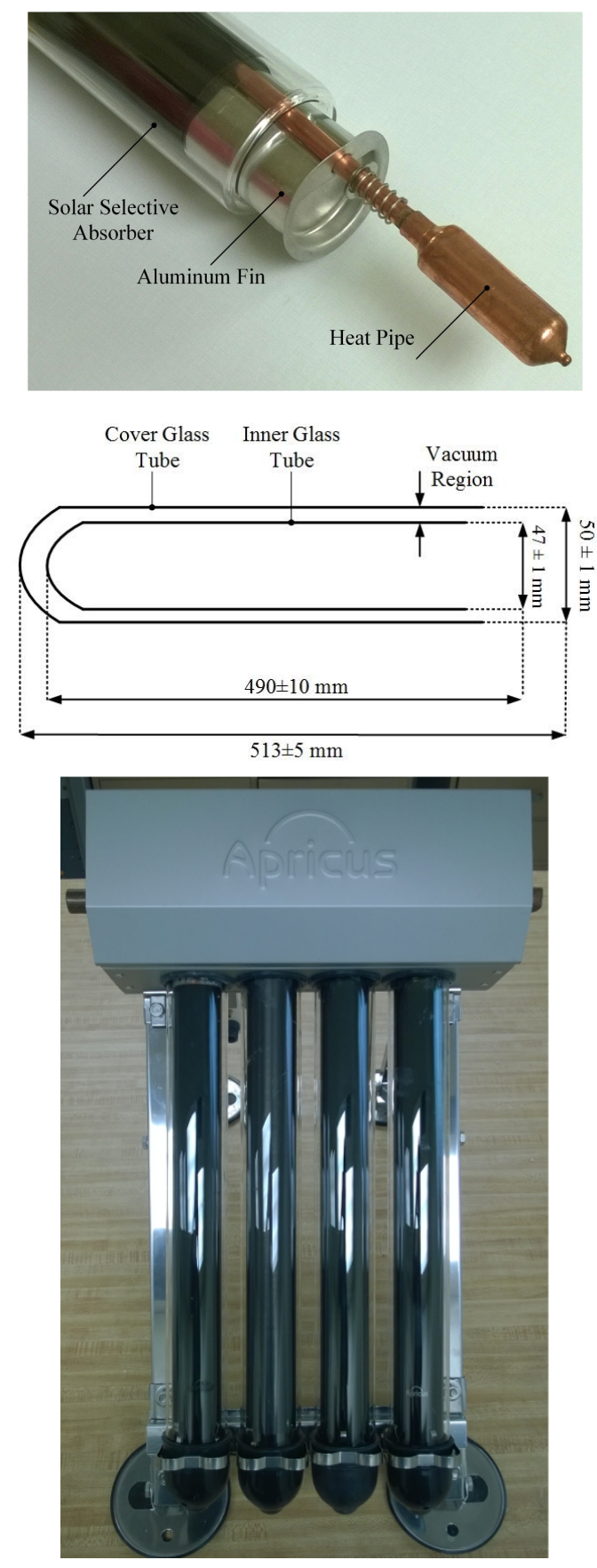

Figure 4: Phase-I: Experimental apparatus 


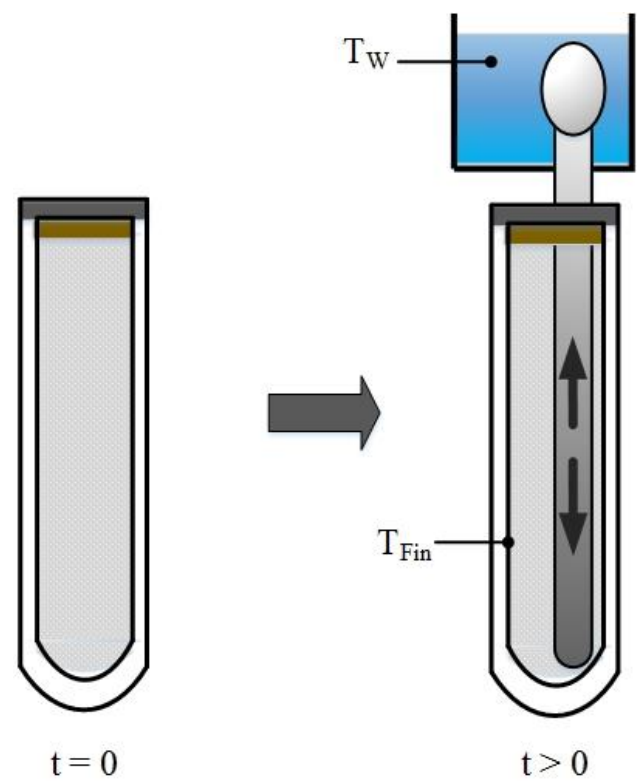

Figure 5: Phase-I: Schematic Configuration of Experimental setup 


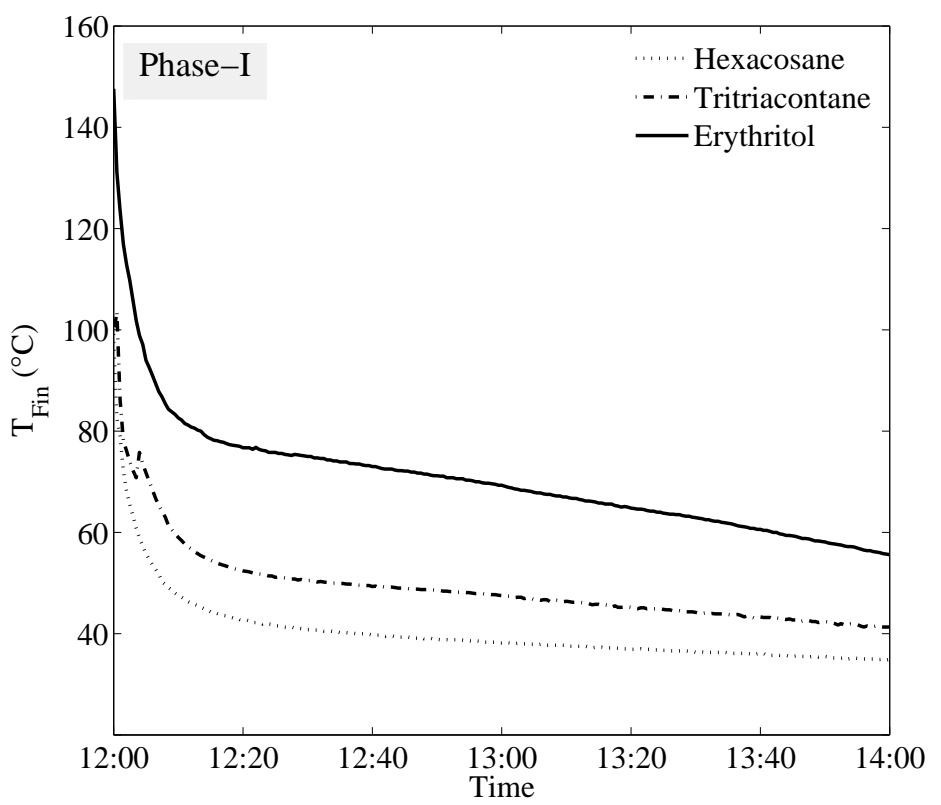

(a)

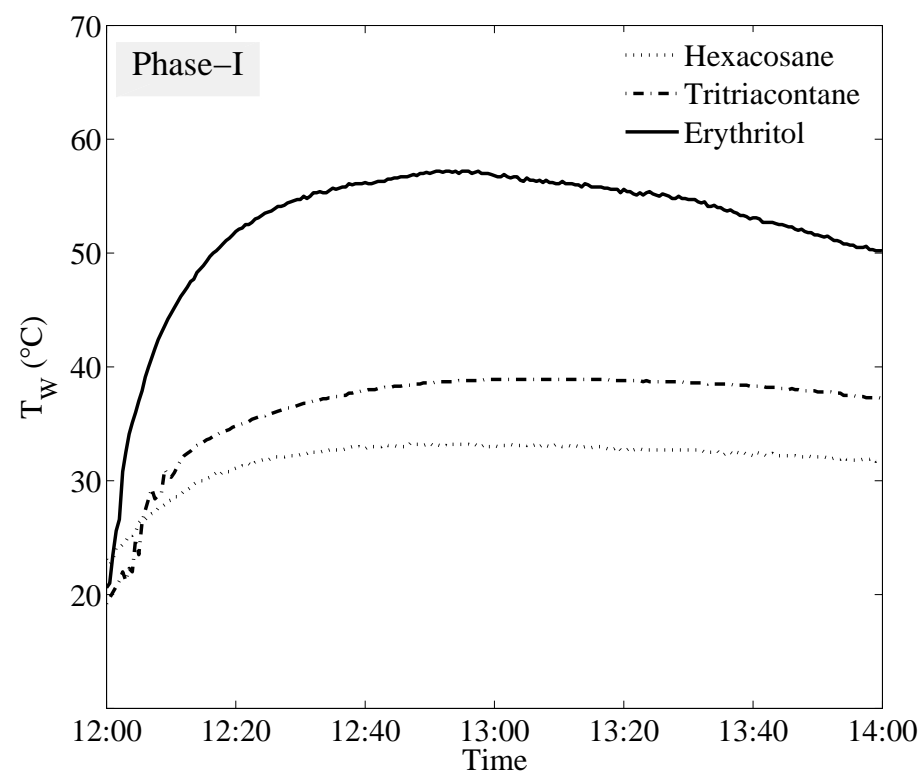

(b)

Figure 6: Phase-I: (top) Temperature inside the tubes, and (bottom) Temperature of the water tank 


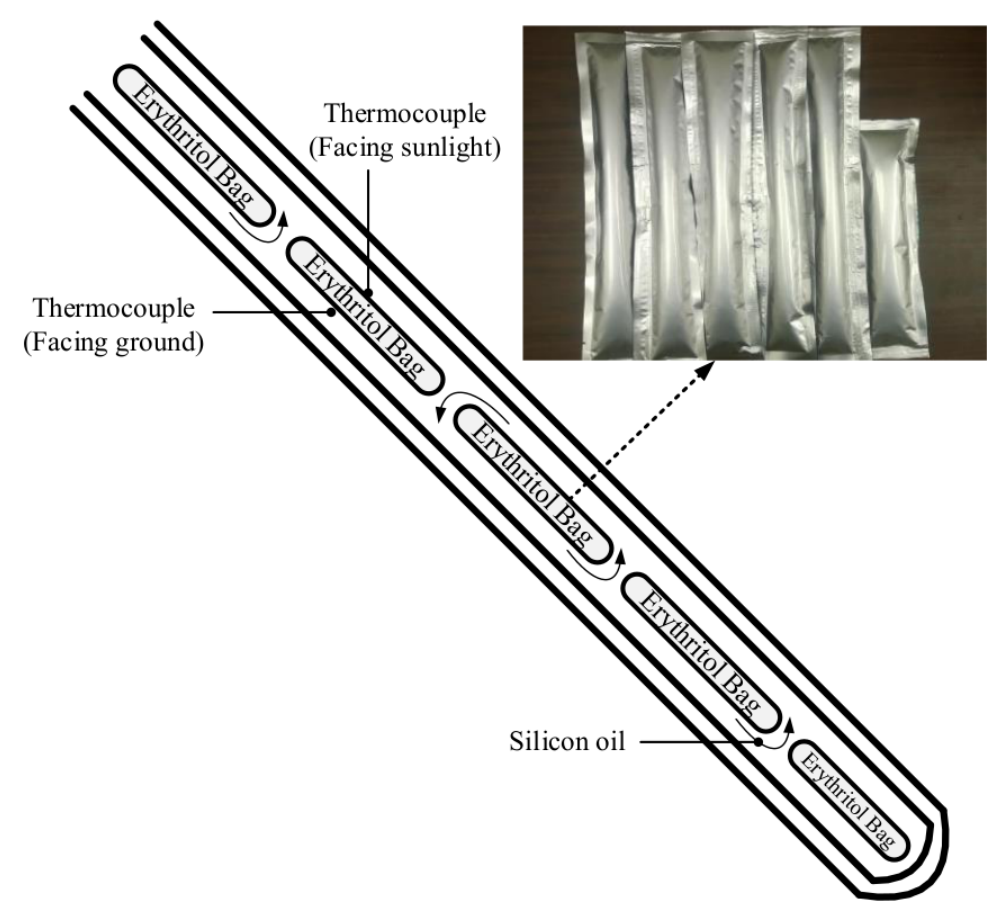

Figure 7: A schematic configuration of evacuated solar tubes filled with Erythritol baggies and silicone oil flow 


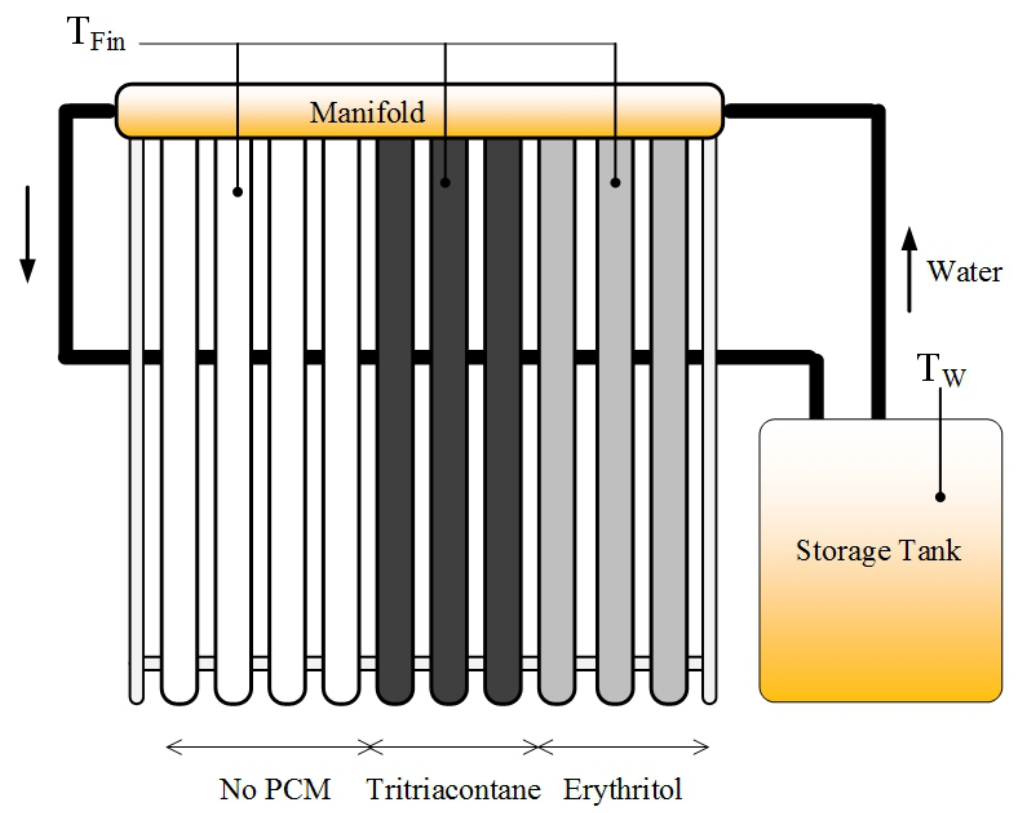

Figure 8: Phase-II: Schematic Configuration of Experimental Setup 


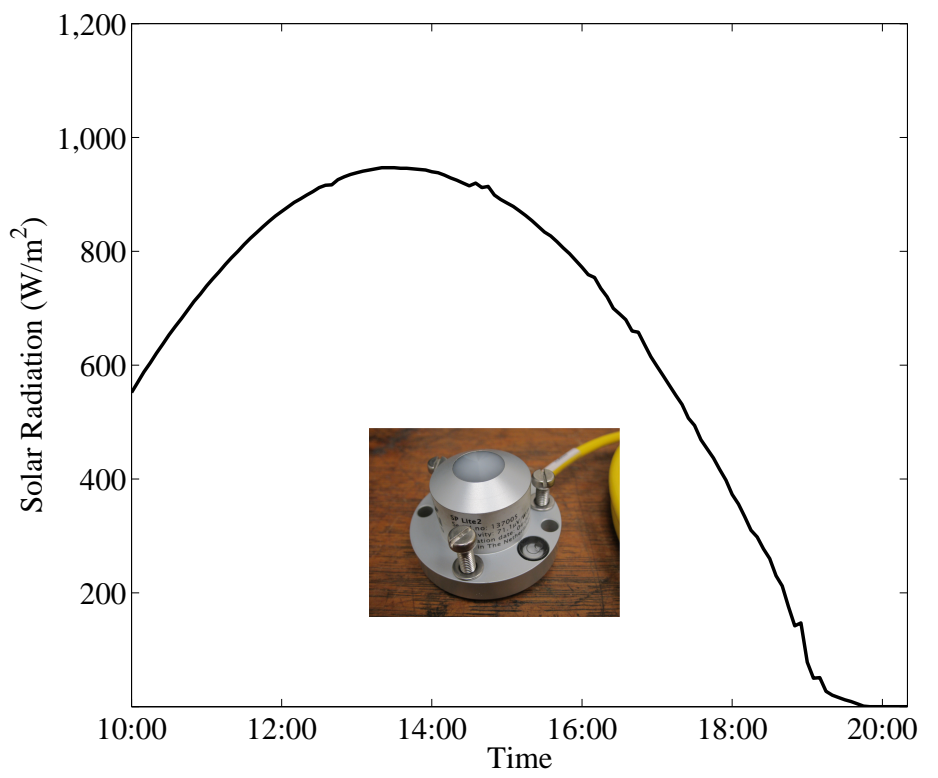

Figure 9: A sample of solar radiation recorded by Pyranometer 


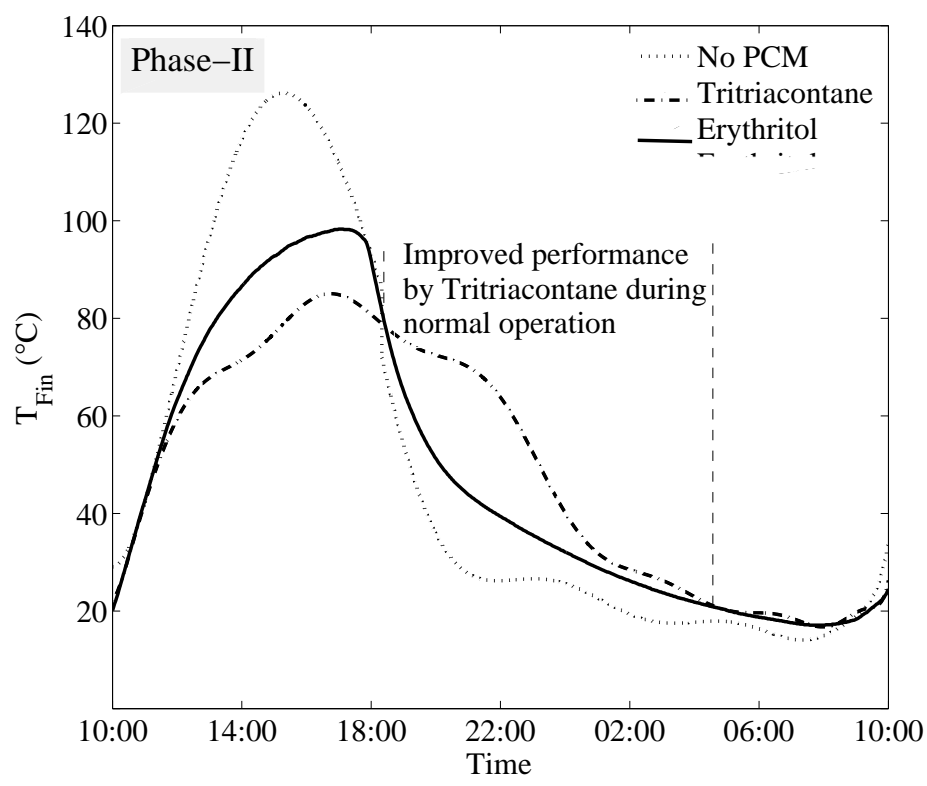

(a)

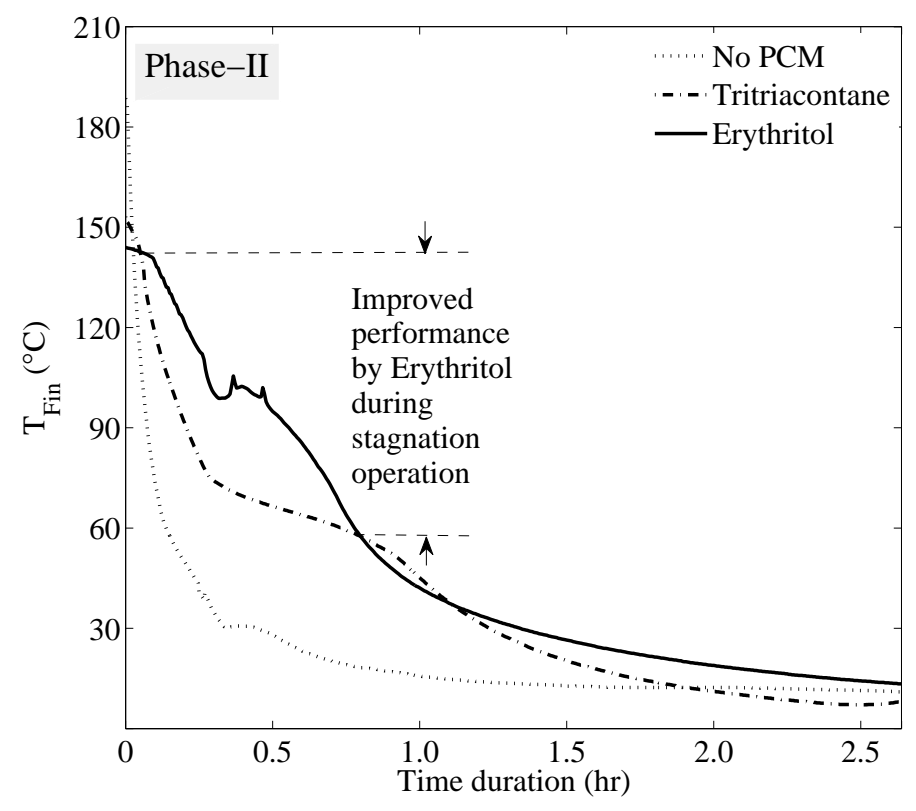

(b)

Figure 10: Phase II: Temperature inside the evacuated tubes, (top) Normal operation, and (bottom) Stagnation operation 


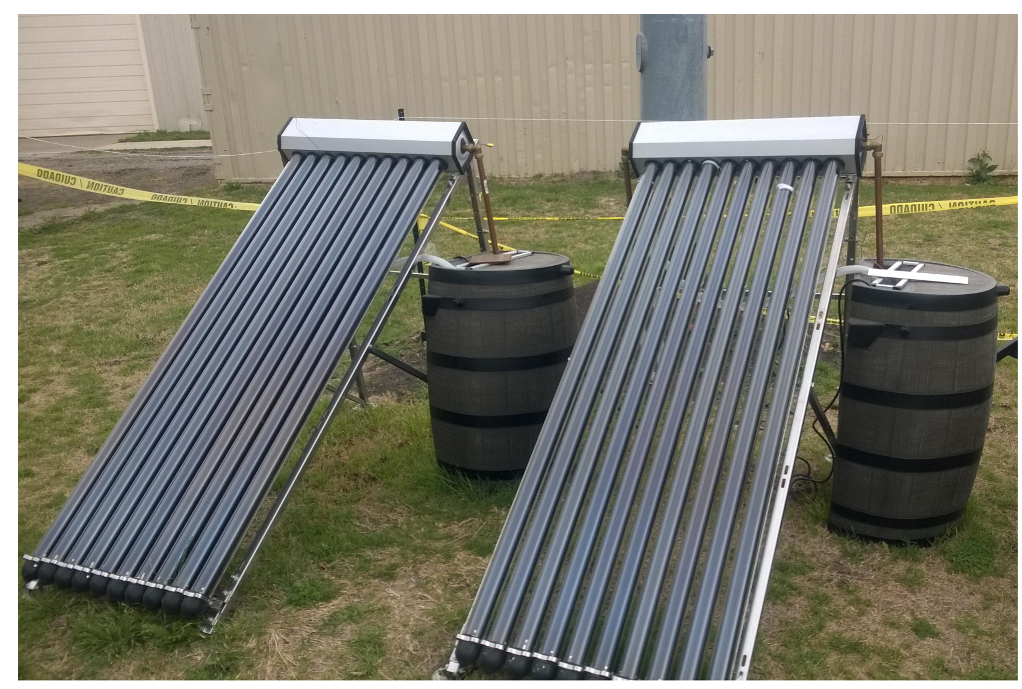

Figure 11: Phase-III: Experimental apparatus 


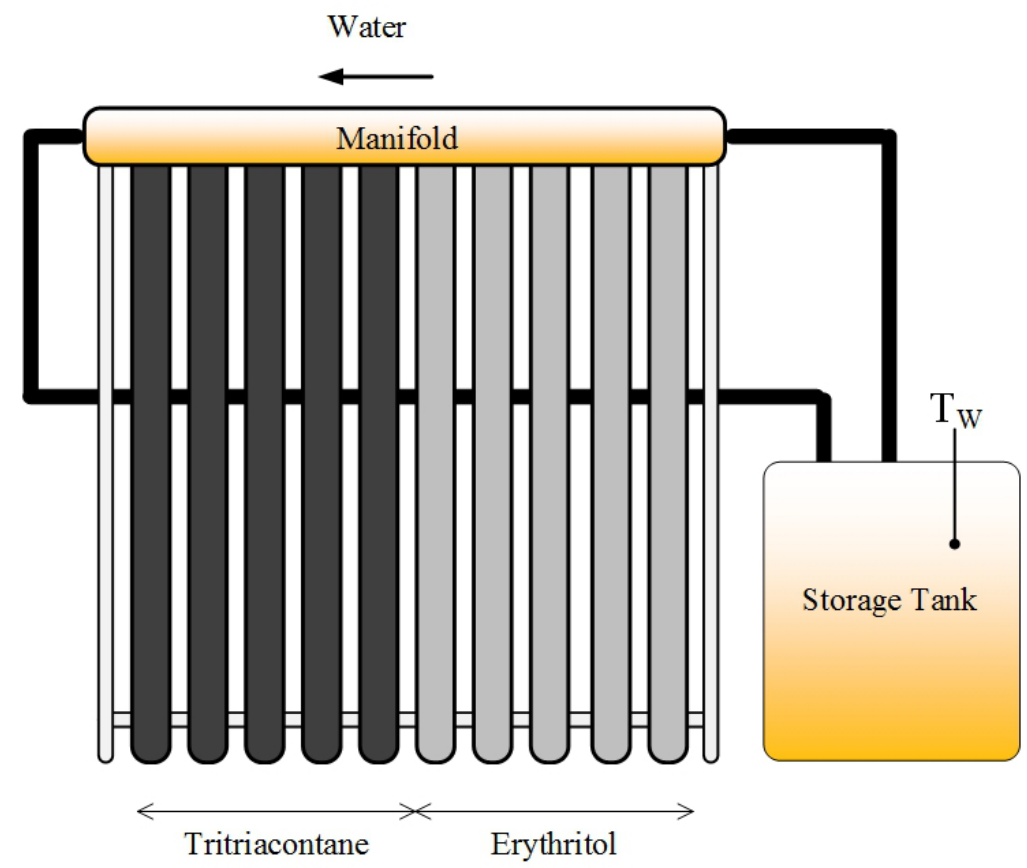

Figure 12: Phase-III: Schematic Configuration of Dual-PCM Experimental Setup 


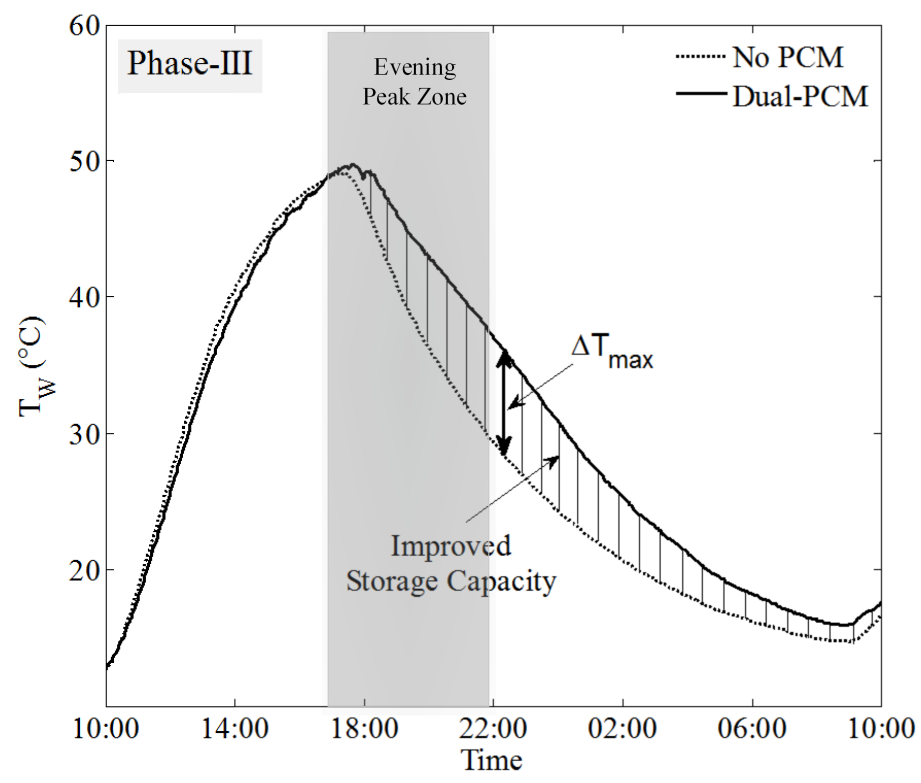

(a)

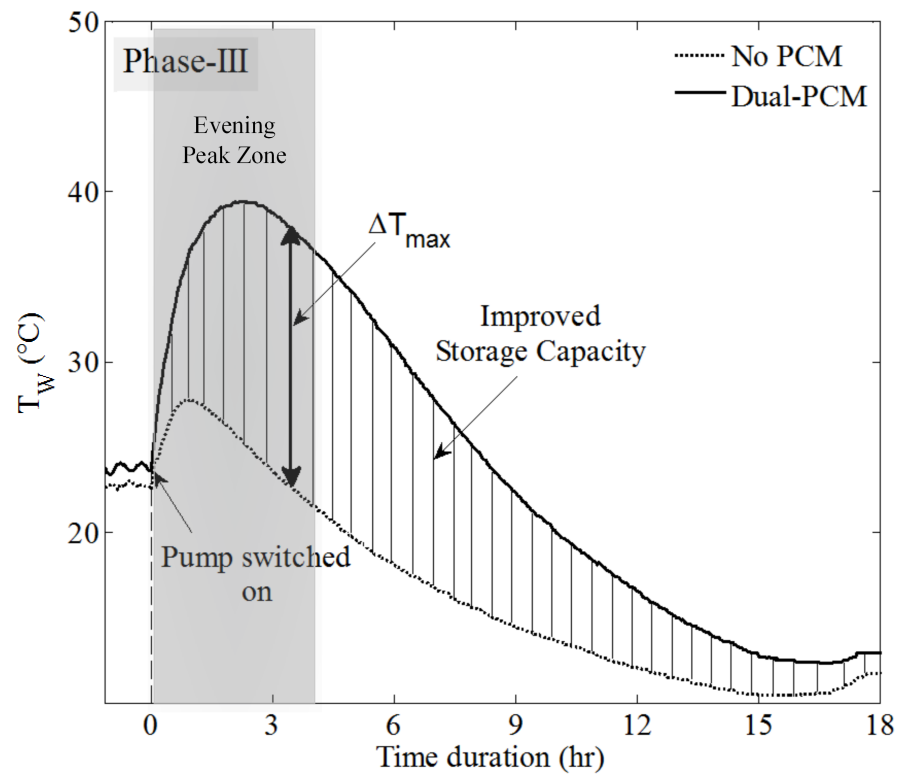

(b)

Figure 13: Phase III: Water temperature, (a) Normal operation, and (b) Stagnation operation 


\section{References}

Al-Jandal, S., Sayigh, A., 1994. Thermal performance characteristics of stc system with phase change storage. Renewable Energy 5, 390-399.

Bansal, N., Buddhi, D., 1992. An analytical study of a latent heat storage system in a cylinder. Energy conversion and management 33, 235-242.

Boy, E., Boss, R., Lutz, M., 1987. A collector storage module-with integrated phase change material. Proc. ISES, Pergamon Press, Hamburg , 36723680 .

Browne, M.C., Lawlor, K., Kelly, A., Norton, B., Mc Cormack, S.J., 2015. Indoor characterisation of a photovoltaic/thermal phase change material system. Energy Procedia 70, 163-171.

Cabeza, L.F., Ibanez, M., Sole, C., Roca, J., Nogués, M., 2006. Experimentation with a water tank including a pcm module. Solar Energy Materials and Solar Cells 90, 1273-1282.

Canbazoğlu, S., Şahinaslan, A., Ekmekyapar, A., Aksoy, Ý.G., Akarsu, F., 2005. Enhancement of solar thermal energy storage performance using sodium thiosulfate pentahydrate of a conventional solar water-heating system. Energy and Buildings 37, 235-242.

Carlos J.Colon, D.S., 2010. Side-by-side Testing of Water Heating Systems: Results from the 2009-2010 Evaluation. Technical Report FSEC-CR-185610. Florida Solar Energy Center. 1679 Clearlake Road, Cocoa, Florida 32922, USA.

El Qarnia, H., 2009. Numerical analysis of a coupled solar collector latent heat storage unit using various phase change materials for heating the water. Energy Conversion and Management 50, 247-254.

Font, J., Muntasell, J., Cardoner, F., 1994. Preliminary study of a heat storage unit using a solid-solid transition. Solar energy materials and solar cells 33, 169-176.

Ghoneim, A., 1989. Comparison of theoretical models of phase-change and sensible heat storage for air and water-based solar heating systems. Solar Energy 42, 209-220. 
Hassan, M.M., Beliveau, Y., 2008. Modeling of an integrated solar system. Building and Environment 43, 804-810.

Himran, S., Suwono, A., Mansoori, G.A., 1994. Characterization of alkanes and paraffin waxes for application as phase change energy storage medium. Energy Sources 16, 117-128.

Kakiuchi, H., Yamazaki, M., Yabe, M., Chihara, S., Terunuma, Y., Sakata, Y., Usami, T., 1998. A study of erythritol as phase change material. Iea Annex 10, 11-13.

Kaygusuz, K., 1995. Experimental and theoretical investigation of latent heat storage for water based solar heating systems. Energy conversion and management 36, 315-323.

Kürklü, A., Özmerzi, A., Bilgin, S., 2002. Thermal performance of a waterphase change material solar collector. Renewable Energy 26, 391-399.

Lee, W.S., Chen, B.R., Chen, S.L., 2006. Latent heat storage in a two-phase thermosyphon solar water heater. Journal of solar energy engineering 128, 69-76.

Mehling, H., Cabeza, L., Hippeli, S., Hiebler, S., 2003. Pcm-module to improve hot water heat stores with stratification. Renewable Energy 28, 699-711.

Mettawee, E.B.S., Assassa, G.M., 2006. Experimental study of a compact pcm solar collector. Energy 31, 2958-2968.

Munro, I., Bernt, W., Borzelleca, J., Flamm, G., Lynch, B., Kennepohl, E., Bär, E., Modderman, J., 1998. Erythritol: an interpretive summary of biochemical, metabolic, toxicological and clinical data. Food and Chemical Toxicology 36, 1139-1174.

Nallusamy, N., Sampath, S., Velraj, R., 2007. Experimental investigation on a combined sensible and latent heat storage system integrated with constant/varying (solar) heat sources. Renewable Energy 32, 1206-1227.

PBL, C., 2000. Phase change material in solar water heater storage system, in: Proceedings of the 8th international conference on thermal energy storage. 
Prakash, J., Garg, H., Datta, G., 1985. A solar water heater with a built-in latent heat storage. Energy conversion and management 25, 51-56.

Rabin, Y., Bar-Niv, I., Korin, E., Mikic, B., 1995. Integrated solar collector storage system based on a salt-hydrate phase-change material. Solar Energy 55, 435-444.

Seeniraj, R., Narasimhan, N.L., 2008. Performance enhancement of a solar dynamic lhts module having both fins and multiple pcms. Solar Energy $82,535-542$.

Sharma, A., Tyagi, V., Chen, C., Buddhi, D., 2009. Review on thermal energy storage with phase change materials and applications. Renewable and Sustainable energy reviews 13, 318-345.

Sharma A, Pradhan N, K.B., 2003. Performance evaluation of a solar water heater having built in latent heat storage unit. Technical Report p. 10915. Advanced thermal energy storage through phase change materials and chemical reactionsfeasibility studies and demonstration projects. 4th workshop. Indore, India.

Sukhatme, K., Sukhatme, S.P., 1996. Solar energy: principles of thermal collection and storage. Tata McGraw-Hill Education.

Takahashi, A.H.H.J.N.H.K., 2013. Direct contact latent heat storage system using erythritol as a latent heat storage material. Thermal Science and Engineering; ISSN:0918-9963 VOL.21, 83-93.

Talmatsky, E., Kribus, A., 2008. Pcm storage for solar dhw: An unfulfilled promise? Solar Energy 82, 861-869.

Tarhan, S., Sari, A., Yardim, M.H., 2006. Temperature distributions in trapezoidal built in storage solar water heaters with/without phase change materials. Energy conversion and management 47, 2143-2154.

Tayeb, A.M., 1993. A simulation model for a phase-change energy storage system: experimental and verification. Energy conversion and management $34,243-250$.

Tayeb, A.M., 1995. Organic-inorganic mixtures for solar energy storage systems. Energy conversion and management 36, 969-974. 
Tiwari, G., Rai, S., Ram, S., Singh, M., 1988. Performance prediction of pccm collection-cum-storage water heater: quasi-steady state solution. Energy conversion and management 28, 219-223.

Waschull, J., Müller, R., Römer, S., . Investigation of Phase Change Materials for Elevated Temperatures. Technical Report. Institute for Air Conditioning and Refrigeration Dresden (ILK Dresden). Department of Applied New Technologies, Bertolt-Brecht-Allee 20, 01309 Dresden, Germany.

Zalba, B., Marın, J.M., Cabeza, L.F., Mehling, H., 2003. Review on thermal energy storage with phase change: materials, heat transfer analysis and applications. Applied thermal engineering 23, 251-283. 